\title{
Current and Future Insight into Human Resources for Health in Greece
}

\author{
Nikolaos Polyzos ${ }^{*}$, Stefanos Karakolias', George Mavridoglou², Panagiotis Gkorezis ${ }^{3}$, \\ Christos Zilidis ${ }^{4}$ \\ ${ }^{1}$ Department of Social Administration and Political Science, Democritus University of Thrace, Komotini, Greece \\ ${ }^{2}$ Department of Health Care Management, ATEI of Peloponnese, Kalamata, Greece \\ ${ }^{3}$ School of Economics, Aristotle University of Thessaloniki, Thessaloniki, Greece \\ ${ }^{4}$ Department of Medical Laboratories, ATEI of Thessaly, Larissa, Greece \\ Email: ${ }^{\text {npolyzos@socadm.duth.gr }}$
}

Received 11 February 2015

\section{Abstract}

Background: In the context of the recent Greek economic crisis and its detrimental impact on healthcare system as well as the complete absence of a mechanism to map and plan human resources, a need for rethinking healthcare workforce management at a national level was emerged. Objectives: The aim of the study was to identify factors that influence the current and future demand for and supply of human resources in the Greek health system by specifying and empirically testing a projection model over the period 2015-2017. Methods: The projection model constituted a combination between a stock-and-flow model and a workforce-to-population ratio approach. This model was applied twice, once concerning total workforce and full track of new graduates and once concerning only public sector. Results: The first application of the model underpinned a sound and rampant oversupply of health professionals. On the other hand, the second application revealed a need for reinforcing public sector in terms of new hires especially of nursing and midwifery staff, and re-distribution of all. Conclusions: The main results indicate that health policy makers could reach an optimal matching between future supply of and demand for healthcare workforce by adjusting the flexible supply components. This presupposes an accurate and stable system of data collection. On the demand side, it is also important to collect demographics and other health-related data that are more indicative of health needs than population metrics.

\section{Keywords}

Human Resources for Health, Planning, Projections, Stock-and-Flow, Workforce-to-Population

\section{Introduction}

Healthcare provision is a highly labor-intensive production process and constitutes one of the most significant sectors to the European economy. Hence, the human resources for health (HRH) planning is of great importance

${ }^{*}$ Corresponding author.

How to cite this paper: Polyzos, N., Karakolias, S., Mavridoglou, G., Gkorezis, P. and Zilidis, C. (2015) Current and Future Insight into Human Resources for Health in Greece. Open Journal of Social Sciences, 3, 5-14. 
(in Europe, HRH occupy between $5 \%$ and $10 \%$ of total workforce) [1]. HRH planning is oriented to effective health outcomes since the right numbers of people with the right skills in the right place at the right time provide the right services to individuals/patients [2]. This dominant approach implies an optimal quantitative and qualitative matching between future supply of and demand for workforce. Thus, it becomes clear that a multispectral approach should be adopted in forecasting the future demographic and population's health needs in conjunction with technological changes, resource constraints and health expenditure stabilization or even reduction [3]. The educational and training curricula across Europe would be readjusted to fast moving changes in the health sector. The health professionals should be equipped with new skills and new responsibilities in order to increase employability and comply with the new health reform requirements. The financial crisis of 2009 has contributed to a redefinition of health objectives, health priorities and the relevant health reforms to tackle the problems of regional health inequalities and the inefficiencies in the production and distribution of health services [4] [5]. Against this background, this paper aims at identifying factors that influence the current and future demand for and supply of human resources in the Greek health system by specifying and empirically testing a projection model over the period 2015-2017. This model should be further used as a dynamic HRH mapping/planning tool and component of the existing information systems of the Greek Ministry of Health $(\mathrm{MoH})$, including all available sources and indicators suggested by relevant studies under projects carried out by contracts between Gesellschaft für Internationale Zusammenarbeit (GIZ) and Democritus University of Thrace (DUTH) under the auspices of $\mathrm{MoH}$.

\section{Methodology}

\subsection{Theoretical Framework and Best Practices}

HRH planning requires the dual performance of supply and demand projections, which ideally should be equivalent at any given time in the future. Regarding the supply side, the vast majority of international literature proposes a stock-and-flow methodology [6], whereby the current workforce ("stock") is adjusted by entrances into and exits out of the labour market ("flows"). Inflows include indicatively: a) domestic new graduates, b) international graduates entering in the education or labour market as e.g. returned migrants and c) trained staff returning to work. Outflows include indicatively: a) retirements, b) deaths, c) dismissals and d) temporary and permanent out-migration. This methodology was recently applied in the USA under the so called "Clinician Specialty Supply Model” (CSSDM), which projects future changes in the supply of clinicians by specialty attributable to their changing demographic composition [7]. Canada's experience on a simulated stock-and-flow model is also worth mentioning. Particularly, the simulation approach was used not to predict the future but to integrate knowledge of different components of the conceptual model in order to improve understanding of the dynamics of the system and analyse strategies and policies to address human resource problems [8]. On the other hand, demand projections usually take into account current population demography and possibly epidemiology, existing health services as well as current numbers of staff of different cadres and skills required. In this context, four alternative methods are proposed to project future health workforce requirements: the workforce-to-population ratio method, the health needs method, the service demands method and the service targets method [6].

\subsection{Data Availability}

In Greece, comprehensive data on human resources were not available in any one repository as there is not a national system tracking at the same time graduates of health professions education programs, international immigration of workers with health-related skills or exits due to career change. This means that any attempt to determine the size and core characteristics of the health workforce requires some level of analysis and synthesis of available information from multiple sources. The first step of our study focused on systematically identifying the supply of workforce in Greek NHS, through gathering and synthesizing data from different available sources and encompassing flows into and out of the health manpower. In particular, we conducted $\mathrm{MoH}$ and other government agencies with HRH roles [e.g. Ministry of Education, Ministry of Labour, Ministry of Administrative Reform and e-Government and Hellenic Statistical Authority (EL.STAT.)], in order to combine different types of information scattered across different sources. HRH data mapping template (WHO, version 2.2 [9]) tool was deemed most suitable for professions' classification and was primarily administered through email exchanges with the above sources. Follow-up telephone interviews were then conducted to complete the template. The availability of supply-related data is summarized in Table 1. It is important to be pointed out that it was infeasi- 
Table 1. Availability of data concerning supply of workforce.

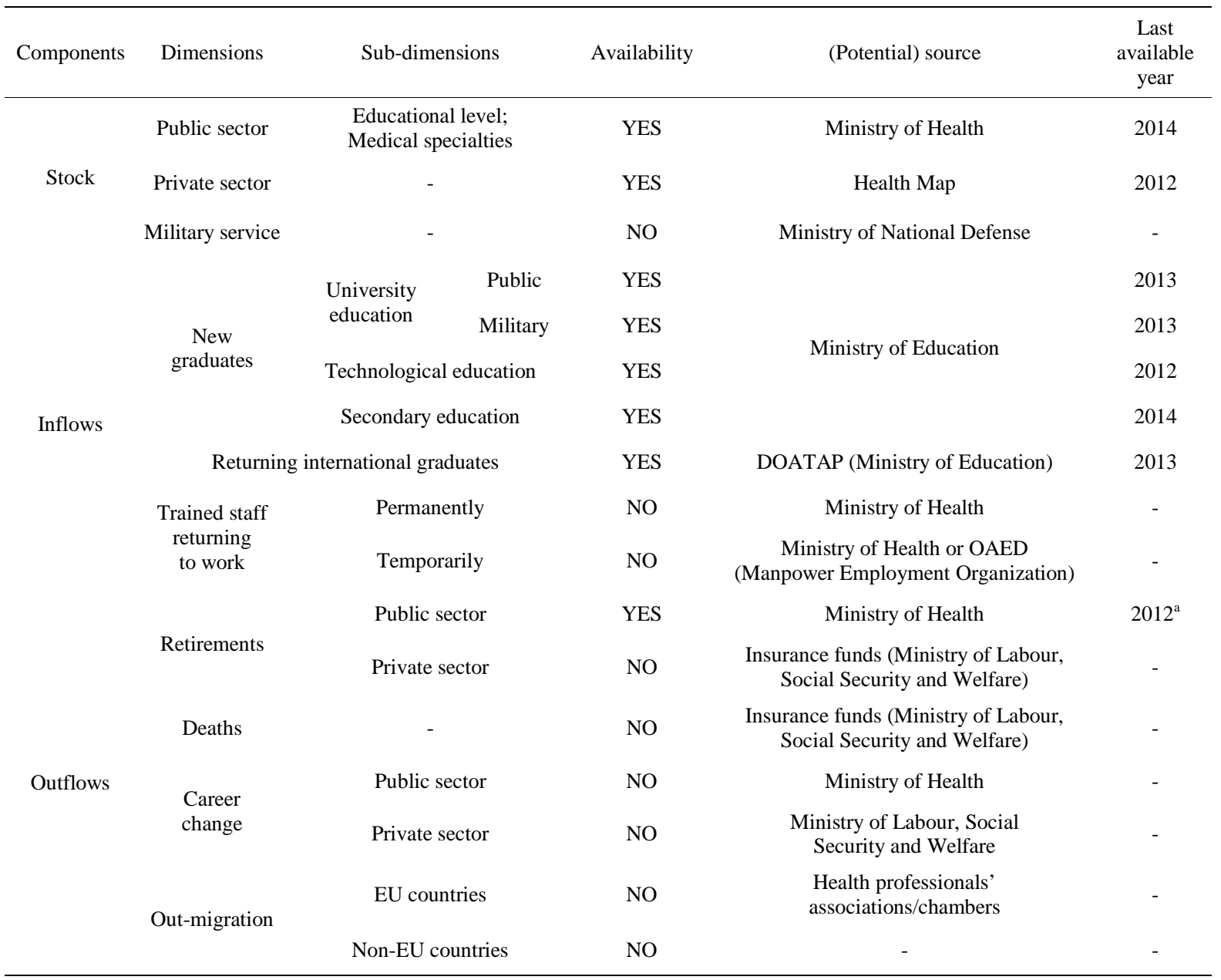

a. Including projections based on eligibility for retirement over the period 2015-2017.

ble to obtain insightful and thorough evidence of outflows. The main reason consists that out-migrants are not recorded at all, whereas insurance funds still fall short of management information systems. Another obstacle is that data were collected from different sources hence there is a little chance to achieve integration, interoperability, unified data format and same reference year.

On the demand side, we only had access to population-related data, and more specifically population projections by Eurostat's EUROPOP2013 (European Population Projections, base year 2013) [10]. The main scenario is demonstrated in Table 2.

According to the adequacy and quality of domestic data combined with the projection alternatives presented above, we applied the workforce-to-population ratio concerning demand projections complementarily to the stockand-flow model concerning supply projections.

\subsection{Modeling}

The modeling of the workforce-to-population ratio method lies upon the last available population-based indicators (base year 2014) as well as the expected population growth (or decline) rate (2015-2017). The main concept of the examined methodology is that the population-based indicators in national level must meet the international standards. Secondly, apart from the international standards (minimum accepted thresholds), the national average density of each health professional category will constitute the threshold density among health regions that is assumed to correspond with the health system's ability to deliver essential health services. Hence, this approach underpins both adjustment in total numbers and geographical reallocation. 
Table 2. Population projections based on Eurostat’s main scenario, 2014-2017.

\begin{tabular}{lc}
\hline Year & Total population \\
\hline 2014 & 11.028 .135 \\
2015 & 10.977 .945 \\
2016 & 10.929 .715 \\
2017 & 10.876 .375 \\
\hline
\end{tabular}

Regarding the stock-and-flow model, the stock/number of trained health professionals $(S)$ in a future year $(t+$ $1, t+2$ etc., where $t$ is the base year) depends on the stock of the current year $\left(S_{t}\right)$ plus the sum of $i$ inflow cases under which health professionals join the workforce $\left(I_{t+1}\right)$ and minus the sum of $j$ outflow cases under which they leave $\left(O_{t+1}\right)$. This model is quantified by Equation (1).

$$
S_{t+1}=S_{t}+\sum I_{i t+1}-\sum O_{j t+1}
$$

\section{Human Resources for Health in Greece}

\subsection{Current Situation}

The current situation (October 2014) of the Greek health system is presented in Table $\mathbf{3}$ which includes almost exclusively salaried staff of both public and private sector. The results reveal an excess of 114 thousand professionals among which $29.1 \%$ constitute medical staff, $23.4 \%$ nursing staff, whereas each of the categories "health associates" and "management/support personnel" stands for circa $1 / 5$ of total workforce. Moreover, the predominant role of public sector is clear (employing over $3 / 4$ of total manpower). This is the current result of the last reforms merging all social insurance units into NHS, since physicians and other staff preferred to pass from public to private system or to be retired. As such, the public sector's hospital care is now even greater than primary care in terms of manpower. Density indicators reveal a physician-driven organizational structure, more intense in private sector, which responds to 2 physicians per 1,000 population in public sector and 3 physicians per 1000 population in total. The aforementioned result is verified when calculating the nurses to physician ratio, which accounts for 0.82 nurses per physician in public sector (or 1.6 when including associates) and 0.81 in total (or 1.3 when including associates). These ratios fall dramatically short of international standards.

However, this situation is rather misleading in terms of the entire NHS since total physicians (including solo practice) account for approximately 69 thousands according to the most recent (2011) figures of EL.STAT. [11], while the same agency has recorded 6629 freelancing physiotherapists in 2013 and 11,315 drugstores in 2011 (hence roughly equal number of freelancing pharmacists), both of them proportionally raising the actual number of "other health professionals". In this vein, international comparisons suggest an oversupply of physicians since the cumulative indicator (total public and private) of 6.2 physicians per 1000 inhabitants (in 2011) is by far the highest in comparison to the average OECD indicator which is slightly above of 3 physicians per 1000 inhabitants [12]. By contrast, there is a certain shortage of Greek nurses since on average there were, in 2009, about 8 nurses per 1000 inhabitants in EU, while the same indicator for Greece was 3.3 (professionals: 1.8; associates: 1.5) [12]. This situation plays a pivotal role in both mitigating organizational commitment and job satisfaction and emerging continued challenges regarding both the quality of patient care and safety [13] [14]. Nevertheless, the figures of Table 3 indicate an improvement as nursing and midwifery professionals have risen at 2.4 per 1000 population over the period 2009-2014, while the density of associates is stable.

In terms of inflows, the domestic education system produces over 9000 new professionals every year (Table 4). The vast majority of them (47.3\%) are classified into "health professionals". It is worth mentioning that, despite the internal production of nurses is higher than that of medical staff by $50 \%$ (or 550 graduates per year), the labour market seems unable to absorb them proportionally (comparison with Table 3). Furthermore, the internal production of health associate professionals accounts for $30 \%$ of total new domestic graduates and the 2/3 of them are not tertiary educated. The technical education production far outnumbers that of Greek universities as regards nursing staff and other health professionals (e.g. physiotherapists receive only technical education). As a result, only $39 \%$ of the total domestic graduates in health-related fields gain a university degree. The total education inflows are complemented with professionals graduated abroad. In 2013, the competent agency re- 
Table 3. NHS staff per professional category, level of care, and public-private mix.

\begin{tabular}{|c|c|c|c|c|c|c|c|}
\hline \multirow{2}{*}{ Professions } & \multicolumn{4}{|c|}{ Public sector } & \multirow{2}{*}{$\begin{array}{c}\text { Private } \\
\text { hospitals } \\
\text { and clinics }\end{array}$} & \multicolumn{2}{|c|}{ Total } \\
\hline & Hospitals $^{\mathrm{a}}$ & $\begin{array}{l}\text { Health } \\
\text { centres }^{\mathrm{a}}\end{array}$ & Subtotal & $\begin{array}{l}\text { Per } 1000 \\
\text { population }\end{array}$ & & $\begin{array}{c}\text { Total } \\
\text { number }\end{array}$ & $\begin{array}{l}\text { Per } 1000 \\
\text { population }\end{array}$ \\
\hline Medical doctors/physicians & 20,530 & 1851 & 22,381 & 2.0 & $10,875^{\mathrm{d}}$ & 33,256 & 3.0 \\
\hline Nursing and midwifery professionals & 17,709 & 748 & 18,457 & 1.7 & 8332 & 26,789 & 2.4 \\
\hline Other health professionals & 2470 & 612 & 3082 & 0.3 & 1778 & 4860 & 0.4 \\
\hline Total health professionals & 40,709 & 3211 & 43,920 & 4.0 & 20,985 & 64,905 & 5.9 \\
\hline Medical and pharmaceutical technicians & 3233 & 465 & 3698 & 0.3 & 0 & 3698 & 0.3 \\
\hline Nursing \& midwifery associate professionals & 16,382 & 476 & 16,858 & 1.5 & 0 & 16,858 & 1.5 \\
\hline Other health associate professionals & 4662 & 308 & 4970 & 0.5 & 0 & 4970 & 0.5 \\
\hline Total health associate professionals & 24,277 & 1249 & 25,526 & 2.3 & 0 & 25,526 & 2.3 \\
\hline Personal care workers & 1347 & 177 & 1524 & 0.1 & 0 & 1524 & 0.1 \\
\hline Administrative & 8018 & 455 & 8473 & 0.8 & 2880 & 11,353 & 1.0 \\
\hline Technical \& other & 8115 & 118 & 8233 & 0.7 & 2810 & 11,043 & 1.0 \\
\hline Health management and support personnel & 16,133 & 573 & 16,706 & 1.5 & 5690 & 22,396 & 2.0 \\
\hline $\begin{array}{l}\text { Health services providers } \\
\text { not elsewhere classified }\end{array}$ & 45 & 0 & 45 & 0.0 & 0 & 45 & 0.0 \\
\hline Total & 82,511 & 5210 & 87,721 & 8.0 & 26,675 & 114,396 & 10.4 \\
\hline
\end{tabular}

a. 2014 data retrieved from Ministry of Administrative Reform and e-Government. b. Based on the 2014 population scenario of Table 2 . c. 2012 data retrieved from Health Map. d. Both salaried and freelancers collaborating with private hospitals.

Table 4. Graduates per profession, level of education and place of graduation.

\begin{tabular}{|c|c|c|c|c|c|c|c|}
\hline \multirow{2}{*}{ Professions } & \multicolumn{4}{|c|}{ Domestic graduates } & \multirow{2}{*}{$\begin{array}{l}\text { International } \\
\text { graduates }^{\mathrm{d}}\end{array}$} & \multicolumn{2}{|c|}{ Total } \\
\hline & University $^{\mathrm{a}}$ & Technical $^{\mathrm{b}}$ & Secondary ${ }^{c}$ & Subtotal & & $\begin{array}{c}\text { Total } \\
\text { number }\end{array}$ & $\begin{array}{l}\text { Per } 100 \\
\text { existing staff }\end{array}$ \\
\hline Medical doctors/physicians & 1017 & - & - & 1017 & 112 & 1129 & 3.4 \\
\hline Nursing and midwifery professionals & 196 & 1379 & - & 1575 & 15 & 1590 & 5.9 \\
\hline Other health professionals & 491 & 1203 & - & 1694 & 123 & 1817 & 37.4 \\
\hline Total health professionals & 1704 & 2582 & 0 & 4286 & 250 & 4536 & 7.0 \\
\hline Medical and pharmaceutical technicians & - & 461 & 541 & 1002 & - & 1002 & 27.1 \\
\hline Nursing \& midwifery associate professionals & - & - & 881 & 881 & - & 881 & 5.2 \\
\hline Other health associate professionals & - & 472 & 369 & 841 & - & 841 & 16.9 \\
\hline Total health associate professionals & 0 & 933 & 1791 & 2724 & 0 & 2724 & 10.7 \\
\hline Personal care workers & 0 & 0 & 0 & 0 & 0 & 0 & 0.0 \\
\hline Administrative $^{e}$ & - & 242 & - & 242 & - & 242 & 2.1 \\
\hline Technical $^{\mathrm{e}} \&$ other & 1809 & - & - & 1809 & 68 & 1877 & 17.0 \\
\hline Health management and support personnel & 1809 & 242 & 0 & 2051 & 68 & 2119 & 9.5 \\
\hline $\begin{array}{l}\text { Health services providers } \\
\text { not elsewhere classified }\end{array}$ & 0 & 0 & 0 & 0 & 0 & 0 & 0.0 \\
\hline Total & 3513 & 3757 & 1791 & 9061 & 318 & 9379 & 8.2 \\
\hline
\end{tabular}

a. 2013 data retrieved from Ministry of Education. b. 2012 data retrieved from Ministry of Education. c. 2014 data retrieved from Ministry of Education. d. 2013 data retrieved from DOATAP (National Academic Recognition Information Centre). e. There are not any university undergraduate programs to produce administrative staff or engineers that are exclusively intended to healthcare despite several general management and technical schools exist. 
corded 318 of them mainly consisting of physicians and pharmacists (“other health professionals”). The ratio of graduates to 100 existing employees shows an average production of 8.2 which is extremely high in case of "other health professionals" (37.4 graduates per 100 existing staff) and "medical and pharmaceutical technicians" (27.1 graduates per 100 existing staff). The former, perforce, choose the freelancing alternative (dentists, pharmacists, dieticians, speech therapists, physiotherapists, etc.), but the latter cannot be absorbed in salaried positions unless approximately $1 / 4$ of existing staff retires annually. However, during the last five years of economic crisis, Greek graduates from abroad are very less compared to previous years.

Concerning outflows (Table 5), the last available report of the Greek MoH [15] forecasts an upward trend of retirements in public sector over the period 2015-2017 mainly due to the rise in the number of staff eligible for retirement (hence rise in the average age). The figures result in cumulative total retirements of 3,552 up to 2017 which stand for $4 \%$ of existing staff. The vast majority of retirements derives from medical staff $(40.7 \%$ of total retirements) and at the same time represents $6.5 \%$ of existing staff. A sound outflow of administrative staff is expected too ( $17.6 \%$ of total retirements or $7.4 \%$ of existing staff). The ratio of graduates to eligible for retirement verifies the rigorous situation described above, namely, the overproduction of several health professionals not only compared to the existing staff numbers but also to the potential job vacancies. Furthermore, HRH planning should contemplate the relevant memorandum obligation of the Greek public sector to hire 1 new employee for every 5 employees leaving, which is under discussion now, at least for health sector.

\subsection{Future Prospects}

The first application of the projection model concerns only salaried staff of public and private sector along with medical freelancers collaborating with private hospitals. The main assumptions made are listed below:

1) The starting stock of the model is the current workforce i.e. 114,396 employees at the end of 2014 (see Table 3).

Table 5. Eligible for retirement staff in public sector per profession, 2015-2017.

\begin{tabular}{|c|c|c|c|c|c|c|c|}
\hline \multirow{2}{*}{ Professions } & \multicolumn{3}{|c|}{ Eligible for retirement } & \multirow{2}{*}{$\begin{array}{c}\text { Total } \\
\text { (potential) } \\
\text { retirements } \\
\text { (2015-2017) }\end{array}$} & \multirow{2}{*}{$\begin{array}{l}\% \text { of total } \\
\text { retirements }\end{array}$} & \multirow{2}{*}{$\begin{array}{l}\% \text { of total } \\
\text { staff in } \\
\text { public sector }\end{array}$} & \multirow{2}{*}{$\begin{array}{l}\text { Graduates } \\
\text { per eligible } \\
\text { for retirement } \\
(2015-2017)^{d}\end{array}$} \\
\hline & 2015 & 2016 & 2017 & & & & \\
\hline Medical doctors/physicians & 401 & 518 & 527 & 1,446 & 40.7 & 6.5 & 2.3 \\
\hline Nursing and midwifery professionals ${ }^{\mathrm{a}}$ & 129 & 158 & 234 & 521 & 14.7 & 2.8 & 9.2 \\
\hline Other health professionals ${ }^{\mathrm{b}}$ & 16 & 27 & 36 & 79 & 2.2 & 2.6 & 69.0 \\
\hline Total health professionals & 546 & 703 & 797 & 2,046 & 57.6 & 4.7 & 6.7 \\
\hline Medical and pharmaceutical technicians ${ }^{\mathrm{b}}$ & 19 & 32 & 43 & 94 & 2.6 & 2.5 & 32.0 \\
\hline Nursing \& midwifery associate professionals ${ }^{\mathrm{a}}$ & 117 & 145 & 213 & 475 & 13.4 & 2.8 & 5.6 \\
\hline Other health associate professionals ${ }^{\mathrm{b}}$ & 25 & 44 & 58 & 127 & 3.6 & 2.6 & 19.9 \\
\hline Total health associate professionals & 161 & 221 & 314 & 696 & 19.6 & 2.7 & 11.7 \\
\hline Personal care workers ${ }^{c}$ & 8 & 2 & 10 & 20 & 0.6 & 1.3 & 0.0 \\
\hline Administrative & 125 & 183 & 316 & 624 & 17.6 & 7.4 & 1.2 \\
\hline Technical \& other & 34 & 48 & 84 & 166 & 4.7 & 2.0 & 33.9 \\
\hline Health management and support personnel & 159 & 231 & 400 & 790 & 22.2 & 4.7 & 8.0 \\
\hline $\begin{array}{l}\text { Health services providers } \\
\text { not elsewhere classified }\end{array}$ & 0 & 0 & 0 & 0 & 0.0 & 0.0 & - \\
\hline Total & 874 & 1,157 & 1,521 & 3,552 & 100.0 & 4.0 & 7.9 \\
\hline
\end{tabular}

a. The MoH incorporates them into the "Nursing” staff category the retirements of which account for 246, 303 and 447 respectively (2015-2017). The total retirements were proportionally allocated to sub-categories based on the proportions extracted from Table 3. b. Retirements of "Scientific \& other" staff were allocated to sub-categories as above. c. Retirements of "N/R" staff were allocated to sub-categories as above. d. Assuming stability of annual numbers of graduates. 
2) Eligible for retirement staff in public sector (Table 5) represents an equivalent outflow. Future retirements in private sector are expected to be proportional to that of public sector (calculated as the current portion of private staff in total staff for each professional category).

3) Domestic and international graduates over the examined period were supposed to be equal to that of the most recent available year.

4) Demand projections were adjusted in order to stabilize the current (Table 3) density of each professional category.

The results of Table 6 demonstrate that Greek HRH (supply) in 2017 is expected to grow by 20.5\% (or 23.5 thousands) compared with that of base year 2014. Several professional groups' growth, like that of "other health professions" (110\%) and "medical and pharmaceutical technicians" (79\%), is much greater than the average, mainly due to the extended production of the corresponding professions by technical and secondary education schools. The aforementioned developments also imply a universal oversupply of human resources in comparison with the normal demand projections. In total, there is a surplus of 8760 health professionals in 2015 estimated to be extended to 25,078 in 2017 given that inflows and outflows follow this standard pattern. It is also important to point out that the expected discrepancy between HRH supply and demand will raise 2018 onwards, if the shrinking population scenarios are verified and inflows into health-related education are not smoothed. The main managerial implication of this first application is a direct need for adjusting enrolments to the labour market's needs. Otherwise, many thousands of new graduates are inevitably forced to change career or emigrate. In other words, it is rather infeasible for the domestic labour market to absorb over 8000 new graduates per year given the current deficient situation in the private sector and the memorandum constraints in the public sector. It should be taken into account that current total unemployment rate is over $25 \%$ while in ages under 30 years is almost double.

In this mode, we applied the projection model again, now including only the NHS public sector, since the so called Troika Memorandum of Understanding included only this type of staff. The main assumptions of this application are as follows:

Table 6. Supply and demand of total workforce, 2015-2017.

\begin{tabular}{|c|c|c|c|c|c|c|c|c|c|}
\hline \multirow{2}{*}{ Professions } & \multicolumn{3}{|c|}{2015} & \multicolumn{3}{|c|}{2016} & \multicolumn{3}{|c|}{2017} \\
\hline & Supply & Demand & Deviation $^{\mathrm{a}}$ & Supply & Demand & Deviation $^{\mathrm{a}}$ & Supply & Demand & Deviation $^{\mathrm{a}}$ \\
\hline Medical doctors/physicians & 33,789 & 33,105 & 684 & 34,148 & 32,959 & 1189 & 34,494 & 32,798 & 1696 \\
\hline Nursing and midwifery professionals & 28,192 & 26,667 & 1525 & 29,553 & 26,550 & 3003 & 30,803 & 26,420 & 4383 \\
\hline Other health professionals & 6652 & 4838 & 1814 & 8426 & 4817 & 3609 & 10,186 & 4793 & 5393 \\
\hline Total health professionals & 68,634 & 64,610 & 4024 & 72,131 & 64,326 & 7805 & 75,489 & 64,012 & 11,477 \\
\hline Medical and pharmaceutical technicians & 4681 & 3681 & 1000 & 5651 & 3665 & 1986 & 6610 & 3647 & 2963 \\
\hline Nursing \& midwifery associate professionals & 17,622 & 16,781 & 841 & 18,358 & 16,708 & 1650 & 19,026 & 16,626 & 2400 \\
\hline Other health associate professionals & 5786 & 4947 & 839 & 6583 & 4926 & 1657 & 7366 & 4902 & 2464 \\
\hline Total health associate professionals & 28,089 & 25,410 & 2679 & 30,592 & 25,298 & 5294 & 33,002 & 25,175 & 7827 \\
\hline Personal care workers & 1516 & 1517 & -1 & 1514 & 1510 & 4 & 1504 & 1503 & 1 \\
\hline Administrative & 11,428 & 11,301 & 127 & 11,425 & 11,252 & 173 & 11,244 & 11,197 & 47 \\
\hline Technical \& other & 12,874 & 10,993 & 1881 & 14,687 & 10,944 & 3743 & 16,451 & 10,891 & 5560 \\
\hline Health management and support personnel & 24,302 & 22,294 & 2008 & 26,111 & 22,196 & 3915 & 27,694 & 22,088 & 5606 \\
\hline $\begin{array}{l}\text { Health services providers } \\
\text { not elsewhere classified }\end{array}$ & 45 & 45 & 0 & 45 & 45 & 0 & 45 & 44 & 1 \\
\hline Total & 122,635 & 113,875 & 8,760 & 130,505 & 113,375 & 17,130 & 137,900 & 112,822 & 25,078 \\
\hline
\end{tabular}

a. Supply minus demand. 
1) The starting point of the model is the current workforce i.e. 87,721 employees at the end of 2014 (see Table 3), reduced at almost 10,000 during last 5 years of the crisis.

2) Eligible for retirement staff (Table 5) represents an equivalent outflow.

3) Domestic and international graduates' numbers were not taken into account since they constitute potential inflow into the labour market.

4) Demand projections were readjusted in order to exclude the contribution of private sector in covering health needs.

The results of Table 7 reveal a totally different situation compared to that of Table 6. More specifically, we expect an undersupply of circa 475 public servants in 2015 that surges by extra 773 employees in 2016 and 1097 employees in 2017. Hence, the New Greek government should cover the forthcoming surplus of populationbased health needs by hiring about 2345 new health professionals up to 2017.

In order to stabilize the current (2014) density of each professional category, these newly recruited staff should consist of 1442 health professionals (physicians: 1,138; nurses \& midwifes: 267; other: 37), 345 health associate professionals (medical \& pharmaceutical technicians: 43; nursing \& midwifery associate professionals: 243; other: 59), 1 personal care worker, 507 administrative and 53 technical staff, and 1 provider not elsewhere classified. However, the analysis of the previous section showed that there is poor compliance to international density standards especially among medical and nursing staff (oversupply of doctors and undersupply of nurses). In the case of public sector and after the proposed hires, physicians are expected to account for 22,073 whereas nurses (including midwifes) for 18,203 and total nursing staff (including associates) for 34,819. So, the corresponding ratio of nurses to physician remains at 0.82 and 1.6 respectively (compared to Table 3 ). In order to converge to European standards ( 2 - 3 nurses per physician) we strongly recommend reallocating the new job vacancies in favor of nursing staff. This reallocation should primarily take place in Primary Health Care where a nurse-oriented mix of health professionals potentially has an important impact on productivity, costs and health outcomes [16] [17].

Table 7. Supply and demand of public sector workforce, 2015-2017.

\begin{tabular}{|c|c|c|c|c|c|c|c|c|c|}
\hline \multirow{2}{*}{ Professions } & \multicolumn{3}{|c|}{2015} & \multicolumn{3}{|c|}{2016} & \multicolumn{3}{|c|}{2017} \\
\hline & Supply & Demand & Deviation $^{\mathrm{a}}$ & Supply & Demand & Deviation $^{\mathrm{a}}$ & Supply & Demand & Deviation \\
\hline Medical doctors/physicians & 21,980 & 22,279 & -299 & 21,462 & 22,181 & -719 & 20,935 & 22,073 & -1138 \\
\hline Nursing and midwifery professionals & 18,328 & 18,373 & -45 & 18,170 & 18,292 & -122 & 17,936 & 18,203 & -267 \\
\hline Other health professionals & 3066 & 3068 & -2 & 3039 & 3054 & -15 & 3003 & 3040 & -37 \\
\hline Total health professionals & 43,374 & 43,720 & -346 & 42,671 & 43,528 & -857 & 41,874 & 43,316 & -1442 \\
\hline Medical and pharmaceutical technicians & 3679 & 3681 & -2 & 3647 & 3665 & -18 & 3604 & 3647 & -43 \\
\hline Nursing \& midwifery associate professionals & 16,741 & 16,781 & -40 & 16,596 & 16,708 & -112 & 16,383 & 16,626 & -243 \\
\hline Other health associate professionals & 4945 & 4947 & -2 & 4901 & 4926 & -25 & 4843 & 4902 & -59 \\
\hline Total health associate professionals & 25,365 & 25,410 & -45 & 25,144 & 25,298 & -154 & 24,830 & 25,175 & -345 \\
\hline Personal care workers & 1516 & 1517 & -1 & 1514 & 1510 & 4 & 1504 & 1503 & 1 \\
\hline Administrative & 8348 & 8434 & -86 & 8165 & 8397 & -232 & 7849 & 8356 & -507 \\
\hline Technical \& other & 8199 & 8196 & 3 & 8151 & 8160 & -9 & 8067 & 8120 & -53 \\
\hline Health management and support personnel & 16,547 & 16,630 & -83 & 16,316 & 16,557 & -241 & 15,916 & 16,476 & -560 \\
\hline $\begin{array}{l}\text { Health services providers } \\
\text { not elsewhere classified }\end{array}$ & 45 & 45 & 0 & 45 & 45 & 0 & 45 & 44 & 1 \\
\hline Total & 86,847 & 87,322 & -475 & 85,690 & 86,938 & -1248 & 84,169 & 86,514 & -2345 \\
\hline
\end{tabular}

a. Supply minus demand. 


\section{Conclusions}

This was the first effort to provide comprehensive evidence of HRH in Greece and further delineate its current and future situation. The main concept was to incorporate the workforce-to-population ratio method into a standard stock-and-flow model in order to initially perform projections over the period 2015-2017 (estimated to finalize the "mid-term program") and afterwards locate any discrepancies from the labour market's equilibrium. The major limitation pertains to the poor evidence of outflows and therefore the first application of the model, that included both public and private sectors' employees and presupposed that health graduates constitute pure inflows, revealed a sound oversupply of health professionals. Furthermore, the second application, that isolated the human capital of private sector and the graduates' effect, showed that the public sector needs reinforcement in terms of new hires especially of nursing and midwifery staff. However, the model's sensitivity to population developments is extremely high and therefore the demand projections should be revised appropriately in an annual basis. Another emerging issue is whether population developments reflect health needs adequately. In any case, demographics, epidemiological and financial data do it better and it is urgent for the Greek MoH to collect such data in 2015 through its core information systems. Thus, the population-oriented projections applied above should be gradually upgraded to a patient's needs-oriented approach presupposing the existence of a mechanism to record and quantify health needs [18].

The greatest challenge is not to apply the model but to produce metadata in the realm of complete lack of a fully comprehensive mapping tool as regards the Greek health workforce. The existing databases are not only fragmented but also confusing since there are several discrepancies and variations in definitions and proposed indicators between them and the WHO's mapping template. Another critical point relates to the fact that Primary Health Care units have been partially recorded in these databases, because regional health authorities have recently undertaken their management from the National Organization for Healthcare Provision (EOPYY). Hence, developing reliable and accurate projection scenarios is impractical under the described circumstances. Even if the existing data (workforce "stock") were updated, adequate and well-fitted, it would be naive to project future supply once again, due to lack of minor data regarding outflows (i.e. career change). A next step of this application should categorize the aforementioned professionals into groups based on, inter alia, working hours, gender, age and other workforce's characteristics in order to combine them with several workloads and efficiency attributes [19]. In this context, standardizing data collection by the competent Ministries and other authorities should constitute the main priority of HRH planning and it could be achieved by developing compact templates.

\section{Acknowledgements}

To GIZ and Research Committee of DUTH who are contracted to proceed HR studies on which this article is based under Pr. Polyzos’ coordination and these authors’ participation.

To Pr. J. Yfantopoulos, Pr. C. Kastanioti, Dr. H. Karanikas, and Mr. Ch. Kakaras for their contribution to the studies.

To Dr. F. Von Renne (GIZ) and V. Kontozamanis (SG of MoH) for their collaboration.

\section{References}

[1] Jelfs, E. (2012) Workforce Issues in European Union Health Policy. Health Service Management Research, 25, 48-49. http://dx.doi.org/10.1258/hsmr.2012.012H01

[2] Birch, S. (2002) Health Human Resource Planning for the New Millennium: Inputs in the Production of Health, Illness and Recovery in Populations. Canadian Journal of Nursing Research, 33, 109-114.

[3] Dreesch, N., Dolea, C., Dal Poz, M., Goubarev, A., Adams, O., Aregawi, M., Bergstrom, K., Fogstad, H., Sheratt, D., Linkins, J., Scherpbier, R. and Youssef-Fox, M. (2005) An Approach to Estimating Human Resource Requirements to Achieve the Millennium Development Goals. Health Policy and Planning, 20, 267-276. http://dx.doi.org/10.1093/heapol/czi036

[4] Staiger, D., Auerbach, D. and Buerhaus, P. (2012) Registered Nurse Labor Supply and the Recession: Are We in a Bubble? New England Journal of Medicine, 366, 1463-1465. http://dx.doi.org/10.1056/NEJMp1200641

[5] Stuckler, D., Basu, S., Suhrcke, M., Coutts, A. and McKee, M. (2011) Effects of the 2008 Recession on Health: A First Look at European Data. Lancet, 378, 124-125. http://dx.doi.org/10.1016/S0140-6736(11)61079-9

[6] World Health Organization (2010) Models and Tools for Health Workforce Planning and Projections. World Health Organization, Geneva. 
[7] Health Resources and Services Administration (2014) Projecting the Supply of Non-Primary Care Specialty and Subspecialty Clinicians: 2010-2025. US Department of Health and Human Services, Rockville.

[8] Birch, S., Kephart, G., Tomblin-Murphy, G., O’ Brien-Pallas, L., Alder, R. and Mac Kenzie, A. (2007) Health Human Resources Planning and the Production of Health: Development of an Extended Analytical Framework for NeedsBased Health Human Resources Planning. SEDAP Research Paper No. 168, McMaster University, Ontario.

[9] World Health Organization (2010) Data Mapping Template on Human Resources for Health. http://www.who.int/hrh/tools/situation_analysis/en/

[10] Eurostat (2014) Population Projections Data. http://ec.europa.eu/eurostat/web/population-demography-migration-projections/population-projections-data

[11] Hellenic Statistical Authority (EL.STAT.) 2011 and 2013 Data. http://www.statistics.gr/

[12] Organization for Economic Cooperation and Development (2014) OECD Health Statistics 2014. http://www.oecd.org/els/health-systems/health-data.htm

[13] Bartram, T. and Dowling, P. (2013) An International Perspective on Human Resource Management and Performance in the Health Care Sector: Toward a Research Agenda. The International Journal of Human Resource Management, 24, 3031-3037. http://dx.doi.org/10.1080/09585192.2013.775024

[14] Buchan, J., O’May, F. and Dussault, G. (2013) The Nursing Workforce and the Global Economic Crisis. Journal of Nursing Scholarship, 45, 298-307.

[15] Ministry of Health (2013) Report on Human Resources in the Greek NHS. (2013). Ministry of Health, Athens.

[16] Laurant, M., Reeves, D., Hermens, R., Braspenning, J., Grol, R. and Sibbald, B. (2004) Substitution of Doctors by Nurses in Primary Care. John Wiley \& Sons Ltd., Chichester.

[17] Horrocks, S., Anderson, E. and Salisbury, C. (2002) Systematic Review of Whether Nurse Practitioners Working in Primary Care Can Provide Equivalent Care to Doctors. BMJ Health Services Research, 324, 819-823. http://dx.doi.org/10.1136/bmj.324.7341.819

[18] O’Brian-Pallas, L., Baumann, A., Donner, G., Murphy, G., Lochhaas-Gerlach, J. and Luba, M. (2001) Forecasting Models for Human Resources in Health Care. Journal of Advanced Nursing, 33, 120-129. http://dx.doi.org/10.1046/j.1365-2648.2001.01645.x

[19] Joyce, C. and McNeil, J. (2006) Participation in the Workforce by Australian Medical Graduates. Medical Education, 40, 333-339. http://dx.doi.org/10.1111/j.1365-2929.2006.02408.x 